\title{
Oxygen Tension Regulates the Expression of the Platelet-derived Growth Factor-B Chain Gene in Human Endothelial Cells
}

\author{
Stella Kourembanas,"*5 Robert L. Hannan," and Douglas V. Faller ${ }^{* 5}$ \\ *Dana Farber Cancer Institute, ${ }^{\ddagger}$ Joint Program in Neonatology, The Children's Hospital, Brigham and Women's Hospital, and \\ Departments of ${ }^{\S}$ Pediatrics and "Surgery, Harvard Medical School, Boston, Massachusetts 02115
}

\begin{abstract}
Hypoxic states are associated with abnormal proliferation and constriction of the smooth muscle cells surrounding the distal vessels of the lung. In hypoxic as well as in normal states, the endothelial cell layer may play a key role in controlling smooth muscle tone by secreting a number of vasoactive agents. Platelet-derived growth factor (PDGF), produced by endothelial cells, is a major growth factor for vascular smooth muscle cells and a powerful vasoconstrictor. It consists of a disulfide-linked dimer of two related peptides, $A$ and $B$, that are products of two different genes. We found that hypoxic conditions (0-3\% oxygen environments) significantly increased PDGF-B mRNA in cultured human umbilical vein endothelial cells by enhancing the transcriptional rate of this gene. This increase was inversely proportional to oxygen tension and was reversible upon reexposure of cells to a $21 \%$ oxygen atmosphere. mRNA levels of PDGF-A were not affected nor was the overall rate of cellular gene transcription increased in response to hypoxia. These studies indicate that endothelial cells are not only capable of sensing oxygen tension, but are also able to discriminate and respond to even small differences in oxygen tension resulting in dramatic upregulation of the PDGF-B chain gene. (J. Clin. Invest. 1990. 86:670-674.) Key words: hypoxia • vasoconstrictor - gene expression - transcriptional regulation - vascular tone
\end{abstract}

\section{Introduction}

Many recent studies have indicated that vascular endothelium regulates smooth muscle vasoactivity. Furchgott and Zawadzki (1) first reported that an intact endothelial cell layer is necessary for the relaxation caused by acetylcholine in isolated rabbit arteries. Since then, endothelial cells have been found to release not only relaxing factors such as prostacyclins and nitric oxide (previously called endothelial-derived relaxing factor) (2), but also a variety of vasoconstrictive agents. Yanagisawa et al. (3) have identified a potent endothelial-derived

Address correspondence and reprint requests to Dr. Douglas V. Faller, Dana Farber Cancer Institute, 44 Binney Street, Boston, MA 02115.

Received for publication 22 January 1990 and in revised form 21 March 1990

J. Clin. Invest.

(c) The American Society for Clinical Investigation, Inc. 0021-9738/90/08/0670/05 \$2.00

Volume 86, August 1990, 670-674 vasoconstrictor, endothelin, and others have described a protease-sensitive vasoconstrictor activity in supernatants of aortic endothelial cells (4). In addition, the endothelium appears to be required for the constrictive effect of hypoxia on isolated canine coronary arteries (5). In 1986, platelet-derived growth factor (PDGF) ${ }^{1}$ was found to be a powerful vasoconstrictive agent for isolated rat aortic strips (6). PDGF is produced and secreted by cells of various normal tissues including endothelial cells. Hence, the regulated local secretion of PDGF within the vasculature could play a crucial role in maintaining smooth muscle tone.

PDGF is a ubiquitous growth factor regulating many biological processes in cells of mesenchymal origin, including proliferation and chemotaxis (7). It has been thought to play a role in normal development as well as in the abnormal proliferation of cells that occur in diseases such as neoplasia, atherosclerosis, and pulmonary fibrosis (8-10). It is composed of two peptides, $A$ and $B$, that are products of two distinct genes and are regulated independently (11, and this report). PDGF is active only in the dimeric form and its biological activity is dependent on the particular homo- or heterodimer interacting with the type and number of specific receptors present on the responding mesenchymal cell. It is synthesized and secreted by various other cell types in addition to endothelial cells, including macrophages and smooth muscle cells. Although smooth muscle cells secrete the AA-dimer exclusively, endothelial cells secrete a mixture of PDGF-BB, -AA, and -AB (12).

The endothelium is in a unique anatomical position in the vasculature to regulate events in the circulating blood cells and the underlying mesenchymal cells. Factors secreted by endothelial cells, such as PDGF, can regulate the proliferative state of the surrounding smooth muscle cells as well as modulate the contractile state of the vasculature. PDGF production in endothelial cells has been shown to be modestly regulated by factors such as thrombin (threefold induction) $(13,14)$, and more dramatically affected by transforming growth factor $\beta\left(\mathrm{TGF}_{\beta}\right)$ (10-fold upregulation) (15). In previous studies we have demonstrated a 10-fold downregulation of PDGF by basic fibroblast growth factor (bFGF) (16). In the studies on early passage cultured endothelium reported here, we explored the possibility that hypoxia, the most potent known physiologic inducer of vasoconstriction, may control vascular smooth muscle tone and blood vessel muscularity by regulating PDGF production in the vasculature.

1. Abbreviations used in this paper: bFGF, basic fibroblast growth factor; PDGF, platelet-derived growth factor; TGF, transforming growth factor. 


\section{Methods}

Cell culture. Primary cultures of human umbilical vein endothelial cells were subcultured on gelatin-coated plates in the presence of heparin $(15 \mathrm{U} / \mathrm{ml})$ and endothelial cell growth supplement (Sigma Chemical Co., St. Louis, MO), in M199 medium (Gibco Laboratories, Grand Island, NY) with 20\% fetal calf serum (Hyclone Laboratories, Logan, UT) at $37^{\circ} \mathrm{C}, 5 \% \mathrm{CO}_{2}$ in a humidified NAPCO incubator. Cells were passaged by trypsinization with $1 \%$ trypsin/EDTA (Gibco Laboratories) every 3-4 d. Endothelial cells at confluence were exposed to various oxygen tensions in air-tight chambers flushed with preanalyzed gas mixtures and maintained at $37^{\circ} \mathrm{C}$.

RNA analysis. Total cellular RNA was prepared by the method of Chirgwin et al. (17), from endothelial cells exposed to various oxygen tensions at confluence. $15 \mu \mathrm{g}$ of RNA/lane were separated by electrophoresis on $1 \%$ agarose gels containing formaldehyde and transferred to nitrocellulose membranes by blotting. The filters were hybridized with a ${ }^{32} \mathrm{P}$-labeled probe specific for the v-sis gene (1300-bp Pst I fragment of Simian Sarcoma Virus Clone C60)(18). v-sis is the Simian Sarcoma Virus oncogene that is homologous to c-sis, the normal Bchain gene of PDGF $(19,20)$. The probe for the human PDGF-A chain gene was a 1300-base pair cDNA clone (21). The $\mathrm{TGF}_{\beta}$ probe used was the 1050-base pair Eco RI fragment corresponding to $\lambda \beta$-C1 (22) coding for human $\mathrm{TGF}_{\beta}$. The actin probe was the 800-base pair Pst I fragment of the mouse $\beta$-actin gene. Hybridization conditions were carried out as previously described (16). For quantitation, transcript levels of c-sis, PDGF-A, or TGF ${ }_{\beta}$ were normalized after densitometry to the levels of actin transcripts, which did not change under the various oxygen environments.

Nuclear runoff analysis. Confluent cultures of endothelial cells exposed to 1 or $21 \%$ oxygen for 48 or $72 \mathrm{~h}$ were lysed and nuclei isolated as described by Kavanaugh et al. (23). $100 \mu \mathrm{l}$ of nuclear suspension were incubated with $0.5 \mathrm{mM}$ each of CTP, ATP, and GTP, and 250 $\mu \mathrm{Ci}$ of $\left[\alpha^{32} \mathrm{P}\right]$ UTP $(3,000 \mathrm{Ci} / \mathrm{mmol}) \mathrm{New}$ England Nuclear, Boston, MA). The samples were phenol/chloroform extracted, precipitated, and resuspended at equal ${ }^{32} \mathrm{P}$-labeled counts $/ \mathrm{ml}$ in hybridization buffer $\left(10-20 \times 10^{6} \mathrm{cpm} / \mathrm{ml}\right)$. Hybridization to denatured probes $(1 \mu \mathrm{g})$ dot blotted on nitrocellulose filters was performed at $40^{\circ} \mathrm{C}$ for $2 \mathrm{~d}$ in the presence of formamide. The filters were washed, treated with RNase A, and exposed to $x$-ray film at $-70^{\circ} \mathrm{C}$ for $2-4 \mathrm{~d}$.

mRNA stability. Endothelial cells at confluence were exposed to $1 \%$ oxygen environment for $2 \mathrm{~d}$. At the end of the incubation period, actinomycin $D$ at a concentration of $5 \mu \mathrm{g} / \mathrm{ml}$ was added (sufficient in preliminary experiments to inhibit incorporation of $\left[{ }^{3} \mathrm{H}\right]$ uridine into RNA). One-half of the cells were placed in a $21 \%$ oxygen environment and the remainder in a $1 \%$ oxygen environment. Cells were harvested at selected time intervals and RNA was analyzed as described above.

\section{Results}

Oxygen tension regulates PDGF-B chain $M R N A$ levels in endothelial cells. Primary cultures of human umbilical vein endothelial cells were incubated for $3 \mathrm{~d}$ in the presence of various concentrations of oxygen. We used RNA blot analysis (Fig. 1 $A$ ) to compare the steady-state PDGF-B transcript levels in endothelial cells exposed to $21 \%$ oxygen with transcript levels obtained when these cells were exposed to $1 \%$ (measured as 30 torr) or $0 \%$ (20 torr) oxygen atmospheres. A radiolabeled cDNA probe for PDGF-B (v-sis) was used for hybridization and the intensity of the bands obtained was quantitated by densitometry and normalized to the actin transcript levels. Increases in PDGF-B mRNA levels of at least eightfold were found in endothelial cells grown in 1\% oxygen atmosphere, compared with levels present when these cells were grown in $21 \%$ oxygen. In addition, more than 10 -fold increases in
A
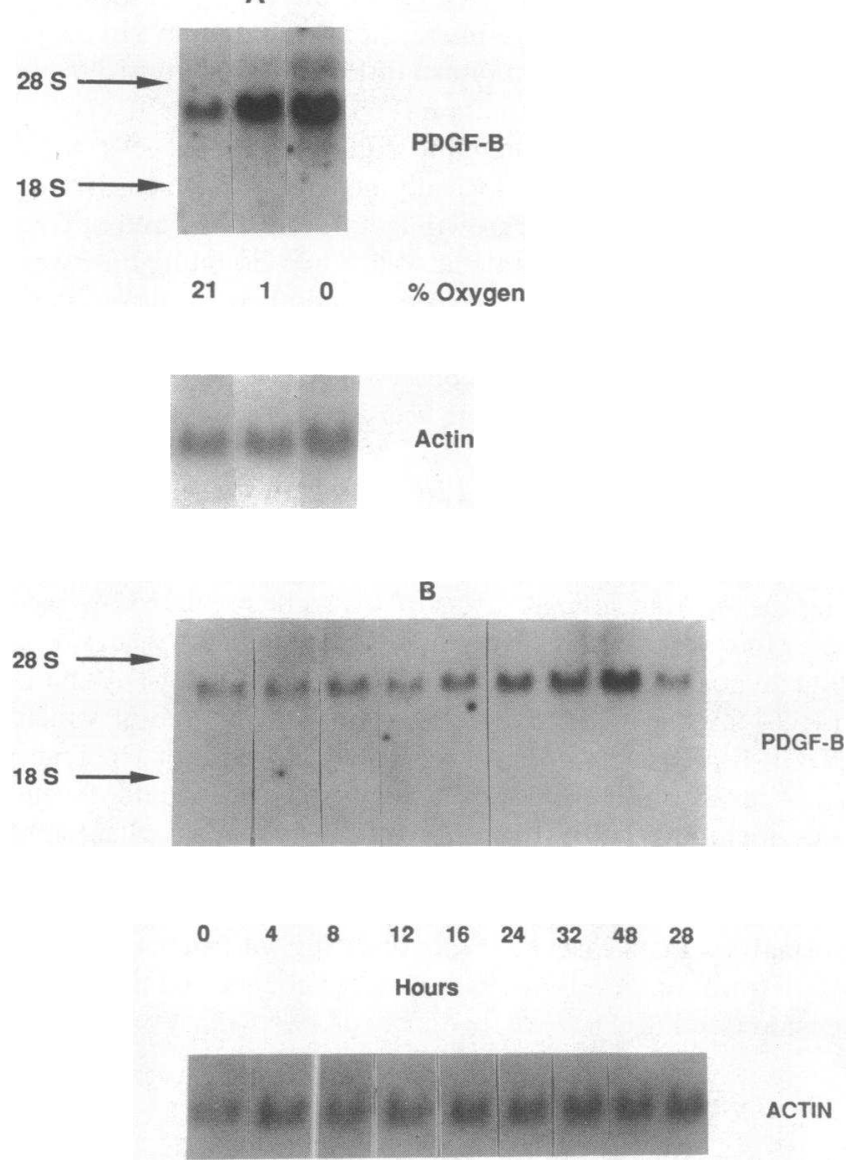

Figure 1. Regulation of PDGF-B chain mRNA by hypoxia in human umbilical vein endothelial cells. $(A)$ Early passage human umbilical vein endothelial cells were grown to confluence in $1 \%$ gelatin-coated tissue culture plates. The cells were allowed to reach confluence at $37^{\circ} \mathrm{C}, 5 \% \mathrm{CO}_{2}$ in a NAPCO incubator, and were then placed in a 21 , 1 , or $0 \%$ oxygen environment with $5 \% \mathrm{CO}_{2}$ for $3 \mathrm{~d}$. The desired oxygen mixture was preanalyzed and infused either continuously onto media at low flow rates $(150 \mathrm{ml} / \mathrm{min})$ or intermittently flushed into air-tight incubators with inflow and outflow valves at a flow rate of 3 liters/min. At the end of the incubation period, total cellular RNA was isolated by the method of Chirgwin et al. (16). $15 \mu \mathrm{g}$ of RNA/ lane were separated by electrophoresis on $1 \%$ agarose gel containing formaldehyde and transferred to nitrocellulose membrane by blotting. The filter was hydridized with ${ }^{32} \mathrm{P}$-labeled probe specific for the sis gene. The filter was stripped and reprobed with actin. $(B)$ Time course of PDGF mRNA regulation by hypoxia. At time 0 , endothelial cells at confluence were given fresh medium and exposed to a $0 \%$ oxygen atmosphere as described in $A$. Total RNA was extracted at the indicated time points $(0,4,8,12,16,24,32,48 \mathrm{~h})$ and RNA blot analysis was performed to evaluate the time required for induction of PDGF-B transcript levels. Partial pressure of oxygen in the medium over the cells reached a nadir of 20 torr between 12 and $24 \mathrm{~h}$ of incubation. The last lane ( $28 h)$ shows PDGF-B mRNA from cells grown in parallel at a $21 \%$ oxygen atmosphere for $28 \mathrm{~h}$. The blot was reprobed with actin as in panel $A$.

PDGF-B transcript levels accumulated in endothelial cells exposed to $0 \%$ oxygen for the same time period in comparison with cells grown in $21 \%$ oxygen conditions. PDGF-B chain mRNA levels increased within $24 \mathrm{~h}$ of exposure to $0 \%$ oxygen and continued to accumulate to higher levels with longer in- 
cubation of cells under hypoxic conditions (Fig. $1 B$ ). Reexposure to a $21 \%$ oxygen atmosphere after incubation in a hypoxic environment resulted in a return of PDGF-B chain mRNA to low (baseline) levels within $24 \mathrm{~h}$ (Fig. $2 \mathrm{~A}$ ).

During the time period of the study, endothelial cells in $0 \%$ oxygen appeared morphologically normal, continued to produce constitutively other growth factors like $\mathrm{TGF}_{\beta}$ and bFGF, and continued to proliferate as well. Their doubling time was somewhat prolonged: at $3 \%$ oxygen, endothelial cells proliferated at a rate equal to that in $21 \%$ oxygen; at $1 \%$ oxygen, the doubling time was twice that observed at $21 \%$ oxygen; while at $0 \%$ oxygen, the doubling time was 2.6 times that observed at $21 \%$ oxygen.

Hypoxia does not affect PDGF-A chain $M R N A$. As endothelial cells are known to express both the B-chain as well as the A-chain genes of PDGF, we investigated the possibility that the A-chain mRNA levels may also be regulated by oxygen. However, as shown by cellular RNA blot analysis in Fig. 2 $B$, a hypoxic environment does not upregulate the A-chain mRNA in these endothelial cells at $48 \mathrm{~h}$ (a time at which PDGF-B mRNA is strongly upregulated; see Fig. $1 \mathrm{~B}$ ). Transcript levels of other growth factors produced by endothelial cells, including $\mathrm{TGF}_{\beta}$ (Fig. $2 \mathrm{~B}$ ), granulocyte-macrophage colony-stimulating factor, and bFGF (data not shown), were also not affected by hypoxia. The amounts of RNA per lane were normalized in all cases after rehybridizing with an actin probe. Actin transcript levels in this system are not affected by oxygen tension (see Fig. 1).
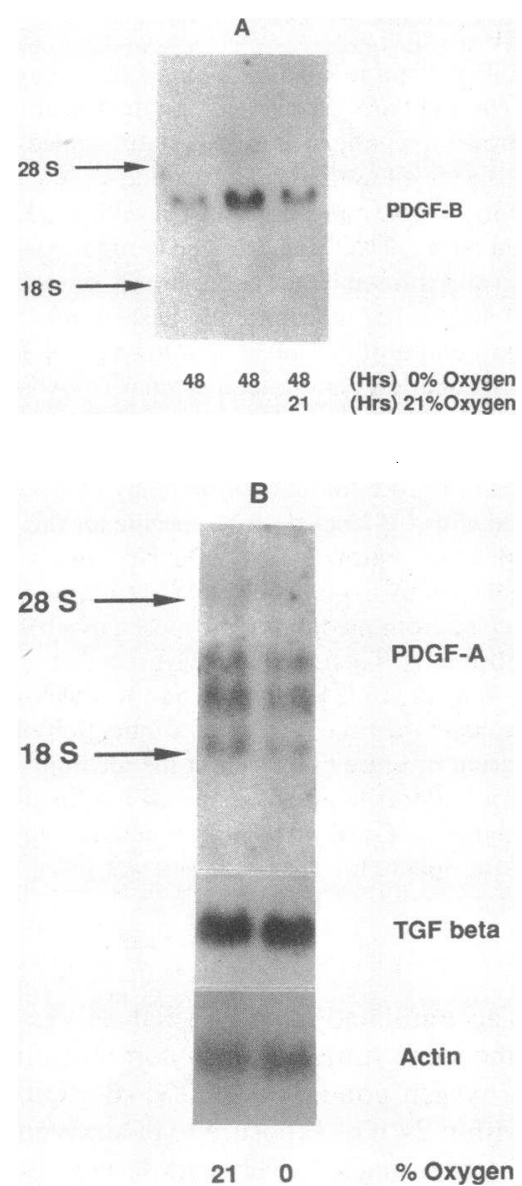

Figure 2. $(A)$ The effect of hypoxia on PDGF is reversible. PDGF-B transcript levels are compared between endothelial cells grown in 0 or $21 \%$ oxygen for 48 h (lane 1 and 2 , respectively) and those present in cells exposed to $0 \%$ oxygen for $48 \mathrm{~h}$ followed by $21 \%$ oxygen for $24 \mathrm{~h}$ (lane 3). (B) Effects of hypoxia on other growth factors. Total cellular RNA was extracted from endothelial cells exposed to 21 or $0 \%$ oxygen environment for $48 \mathrm{~h}$, and Northern analysis was performed. The blot was hybridized to a radiolabeled ${ }^{32} \mathrm{P}$-labeled human PDGF-A chain probe, and after autoradiography was performed the filter was stripped and reprobed with a cDNA probe for $\mathrm{TGF}_{\beta}$. As a control, the hybridization to a radiolabeled actin probe is shown at the bottom.
Effect of hypoxia on transcriptional rate of the PDGF-B gene. To determine whether the increased steady-state PDGF$B$ mRNA levels in the presence of hypoxia were a result of enhanced gene transcription or RNA stability, nuclear runoff analyses were carried out. Transcriptional rates were determined $48 \mathrm{~h}$ after exposure to a 21 or $1 \%$ oxygen environment and were compared with those of the actin gene. As shown in Fig. $3 A, 1 \%$ oxygen stimulated B-chain transcription about 10 -fold (by densitometry) above the rate observed at $21 \%$ oxygen. Actin is transcribed at an equal rate both at 21 and $1 \%$ oxygen environments. The half-life of the PDGF-B transcript was $90 \mathrm{~min}$ in $1 \%$ oxygen and $60 \mathrm{~min}$ in $21 \%$ oxygen as determined by actinomycin-D chase experiments (data not shown). Thus, the stability of the PDGF-B transcript is slightly prolonged by hypoxia but not so significantly as to account for a 10-fold difference in mRNA levels. The increase in PDGF-B mRNA levels in human umbilical vein endothelial cells is therefore predominantly due to increased gene transcription induced by hypoxia and not to enhanced stability of its mRNA.

Relative B-chain transcript levels (with the mRNA levels at $21 \%$ oxygen being made equal to 1 ) are compared among the different oxygen environments in Fig. $3 B$. The accumulation of PDGF-B chain mRNA was progressively enhanced when endothelial cells were exposed to $21,3,1$, and $0 \%$ oxygen tensions. The greatest effect was observed between 0 and $3 \%$ oxygen environments. While $3 \%$ oxygen resulted in a twofold induction of PDGF-B mRNA over the level observed at $21 \%$

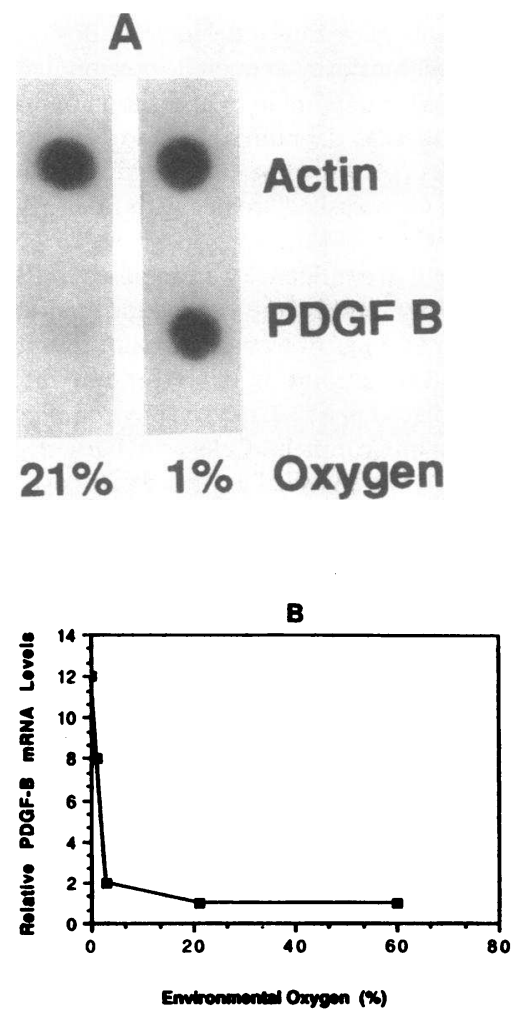

Figure 3. (A) Effect of hypoxia of PDGF-B gene transcription. Endothelial cells at confluence were exposed to 1 or $21 \%$ oxygen environments for $48 \mathrm{~h}$ as previously described. Nuclei were isolated and ${ }^{32} \mathrm{P}$-labeled nuclear runoff products were hybridized to denatured cDNAs of the sis and actin genes spotted onto nitrocellulose filters. Shown are representative data of at least three independent experiments. (B) PDGF-B gene expression is inversely related to oxygen tension. Relative PDGF-B mRNA levels from at least 20 indendent experiments are plotted against levels in environmental oxygen to which the endothelial cells were exposed $(0,1$, 3,21 , and $60 \%$ oxygen) Cells were exposed to hypoxia for various time periods ( $24 \mathrm{~h}-3 \mathrm{~d}$ ) and a significant induction in PDGF-B mRNA was always observed. In six separate experiments performed at the 48-h time point, the mean increase in PDGF-B mRNA in response to $1 \%$ oxygen environment was 7.2 -fold greater than that obtained at $21 \%$ oxygen. 
oxygen, 0 and $1 \%$ oxygen resulted in $\sim 10$-fold induction. No effect on PDGF-B mRNA levels was observed in enironments with oxygen tensions higher than $21 \%$ (ranging up to $60 \%$ ).

\section{Discussion}

Limited information is currently available about the direct influence of hypoxia on biologic activities and functions of the endothelium. Other investigators have shown that endothelial cell proliferation at $3 \%$ oxygen occurs at a rate similar to that of cells exposed to $21 \%$ oxygen but that cells fail to proliferate in complete anoxia (24). High affinity uptake of serotonin is stimulated in endothelial cells exposed to hypoxia (25), while synthesis and release of heparan sulfate by bovine pulmonary artery endothelial cells is inhibited by $3 \%$ oxygen (26). Rounds et al. (27) have reported that cultured endothelial cells release a chemoattractant for neutrophils in response to hypoxia. In the studies presented here, we have shown that hypoxia dramatically increases PDGF-B chain mRNA in human umbilical vein endothelial cells. This effect does not appear to be a nonspecific toxic phenomenon of hypoxia, as evidenced by continued cell growth (albeit at a slower rate in $0 \%$ oxygen environment) and the unaltered expression of transcripts for other growth factors $\left(\mathrm{TGF}_{\beta}\right.$, granulocyte-macrophage colony stimulating factor, and bFGF) and structural proteins (actin) by the endothelial cells. Furthermore, the effect of hypoxia on elevating PDGF transcript levels is reversible.

No significant difference in amounts of PDGF-BB protein produced under the different oxygen environments could be determined by mitogenic assays on growth-arrested fibroblasts, PDGF receptor autophosphorylation, or by metabolic labeling with $\left[{ }^{35} \mathrm{~S}\right]$ methionine/cysteine. PDGF-like protein was detected in small amounts $\left(\sim 1 \mathrm{ng} / 10^{6}\right.$ cells $\left./ 24 \mathrm{~h}\right)$ both in the conditioned media as well as in cell lysates from endothelial cells exposed to 0,1 , or $21 \%$ oxygen environments. Based on our studies of mRNA levels, the upregulation of PDGF-B transcripts with hypoxia should result in increased production of the B chain. Since the A chain is not affected by hypoxia and PDGF is active only in the dimeric form, increased amounts of the PDGF-BB homodimer should be produced. Bowen-Pope et al. (12) have reported the PDGF-BB dimer to be the least abundant PDGF species, comprising only $15 \%$ of the total PDGF secreted by endothelial cells in culture. Even the most sensitive assays used (mitogenesis and receptor autophosphorylation) could not distinguish between the different dimers. Therefore, relatively large increases in the PDGF-BB dimer product, resulting from exposure of endothelial cells to hypoxia, may be difficult to detect within a larger pool of various PDGF dimers. Other inducers of PDGF-A and -B, such as thrombin, $\mathrm{TGF}_{\beta}$, and phorbol esters, result in a maximum of three- to fivefold increases in total PDGF protein production, despite a 10 -fold induction of the gene at the pretranslational level $(14,15)$. If this were the case in our system, even a threeto fivefold difference in a relatively small fraction of the total PDGF produced by endothelial cells in culture may result in an undetectable increment over the prolonged (2-3 d) incubation periods used in our experimental systems. Furthermore, differences in compartmentalization, stability, and function of the various PDGF dimers in vivo are also difficult to reproduce in a culture system. Finally, it is less likely but possible that changes in transcription may not correlate with similar changes in translation. Quantitation of the PDGF-BB dimer intra- as well as extracellularly after various periods of hypoxia are ongoing in our laboratory.

Extrapolation of our findings of transcriptional upregulation of PDGF-B by hypoxia to microvascular endothelial cells suggests that upregulation of PDGF production by the endothelium may be one of the mechanisms responsible for the local regulation of ventilation and perfusion in the lung and for the smooth muscle hypertrophy and vasoconstriction of the pulmonary vasculature seen in response to chronic hypoxia. This regulation occurs over a narrow and physiologic range of oxygen tension, $0-3 \%$ environmental oxygen (20-45 torr) (see Fig. 3 B.) No further effect is seen on PDGF transcript levels at higher oxygen tension. Studies in our laboratory have shown that the endothelial cell oxygen sensor controlling PDGF production is a heme-containing protein (Kourembanas, S., and D. V. Faller, manuscript in preparation). This narrow and sensitive range of response to oxygen tension might therefore reflect a cooperative effect at the molecular level like that responsbile for the sigmoidal shape of the oxygen-hemoglobin association curve. Endothelial cells in various microvascular beds, like the fetal lung, are normally exposed to $\sim 20$ Torr of oxygen. The persistent abnormal vasoconstriction and smooth muscle hypertrophy of pulmonary hypertension in the neonate is observed at similar low oxygen levels, conditions that we have shown to result in PDGF upregulation. Thus, the unique anatomical location of vascular endothelial cells, and the fact that they can sense and respond to small changes in oxygen tension, make them attractive candidates as important local regulators of vascular tone and muscularity.

\section{Acknowledgments}

We thank Drs. Merton Bernfield, Mary Ellen Avery, and Susan Perrine for critical review of the manuscript and valuable advice.

Dr. Faller was supported by research grants from the American Cancer Society, The National Institutes of Health, and The Council for Tobacco Research. The American Lung Association supported Dr. Kourembanas. Dr. Faller is the recipient of a Senior Faculty Award from the American Cancer Society. Dr. Kourembanas is the recipient of a Clinical Investigator Award, and a Charles H. Hood/Medical Foundation Fellowship.

\section{References}

1. Furchgott, R. F., and J. V. Zawadzki. 1980. The obligatory role of endothelial cells in the relaxation of arterial smooth muscle by acetylcholine. Nature (Lond.). 288:373-376.

2. Palmer, R. M. J., A. G. Ferrige, and S. Moncada. 1987. Nitric oxide relese accounts for the biological activity of endothelium-derived relaxing factor. Nature (Lond.). 327:524-526.

3. Yanagisawa, M., H. Kurihara, S. Kimura, Y. Tomobe, M. Kobayashi, Y. Mitsui, Y. Yazaki, G. Katsutoshi, and T. Masaki. 1988. A novel potent vasoconstrictor peptide produced by vascular endothelial cells. Nature (Lond.). 332:411-415.

4. Hickey, K. A., G. Rubanyi, and R. J. Paul. 1985. Characterization of a coronary vasoconstrictor produced by cultured endothelial cells. Am. J. Physiol. 248:C550-C556.

5. Rubanyi, G. M., and P. M. Vanhoutte. 1985. Hypoxia releases a vasoconstrictor substance from the canine vascular endothelium. $J$. Physiol. 364:45-56.

6. Berk, B. C., R. W. Alexander, T. A. Brock, M. A. Gimbrone, and 
R. C. Webb. 1986. Vasoconstriction: a new activity for platelet-derived growth factor. Science (Wash. DC). 232:87-89.

7. Grotendorst, G. R., T. Chang, H. E. J. Seppa, H. K. Kleinman, and G. Martin. 1982. Platelet-derived growth factor is a chemoattractant for vascular smooth muscle cells. J. Cell. Physiol. 113:261-266.

8. Goustin, A. S., C. Betsholtz, S. Pfeifer-Ohlsson, H. Persson, J. Rydnert, M. Bywater, G. Holmgren, C.-H. Heldin, B. Westermark, and R. Ohlsson. 1985. Coexpression of the sis and myc proto-oncogenes in developing human placenta suggests autocrine control of trophoblast growth. Cell. 41:301-312.

9. Ross, R. 1986. The pathogenesis of atherosclerosis: an update. $N$ Engl. J. Med. 314:488-500.

10. Martinet, Y., W. N. Rom, G. R. Grottendorst, G. R. Martin, and R. G. Crystal. 1987. Exaggerated spontaneous release of plateletderived growth factor by alveolar macrophages from patients with idiopathic pulmonary fibrosis. N. Engl. J. Med. 317:202-209.

11. Starksen, N. F., G. R. Harsh, V. C. Gibbs, and L. T. Williams. 1987. Regulated expression of the platelet-derived growth factor: a chain gene in microvascular endothelial cells. J. Biol. Chem. 262:14381-14384.

12. Bowen-Pope, D. F., C. E. Hart, and R. A. Seifert. 1989. Sera and conditioned media contain different isoforms of platelet-derived growth factor (PDGF) which bind to different classes of PDGF receptor. J. Biol. Chem. 264:2502-2508.

13. Harlan, J. M., P. J. Thompson, R. R. Ross, and D. F. BowenPope. 1986. $\alpha$-Thrombin induces release of platelet-derived growth factor-like molecule(s) by cultured human endothelial cells. J. Cell. Biol. 103:1129-1133.

14. Daniel, T. O., V. C. Gibbs, D. F. Milfay, M. R. Garovoy, and L. T. Williams. 1986. Thrombin stimulates $c$-sis gene expression in microvascular endothelial cells. J. Biol. Chem. 261:9579-9582.

15. Daniel, T. O., V. C. Gibbs, D. F. Milfay, and L. T. Williams. 1987. Agents that increase cAMP accumulation block endothelial $c$-sis induction by thrombin and transforming growth factor- $\beta$. J. Biol. Chem. 262:11893-11896.

16. Kourembanas, S., and D. V. Faller. 1989. Platelet-derived growth factor production by human umbilical vein endothelial cells is regulated by basic fibroblast growth factor. J. Biol. Chem. 264:44564459.
17. Chirgwin, J. M., A. E. Przybyla, R. J. MacDonald, and W. J. Rutter. 1979. Isolation of biologically active ribonucleic acid from sources enriched in ribonuclease. Biochemistry. 18:5924-5929.

18. Gelmann, E. P., E. Petri, A. Cetta, and F. Wong-Staal. 1982. Deletions of specific regions of the simian sarcoma-associated virus genome are found in defective viruses and in the simian sarcoma virus. J. Virol. 41:593-604.

19. Deuel, T. F., and J. S. Huang. 1984. Roles of growth factor activities in oncogenesis. Blood. 64:951-958.

20. Stiles, C. D. 1983. The molecular biology of platelet-derived growth factor. Cell. 33:653-655.

21. Betsholtz, C., A. Johnson, C.-H. Heldin, B. Westermark, P. Lind, M. S. Urdea, R. Eddy, T. B. Shows, K. Philpott, A. L. Mellor, T. J. Knott, and J. Scott. 1986. cDNA sequence and chromosomal localization of human platelet-derived growth factor A-chain and its expression in tumour cell lines. Nature (Lond.). 320:695-699.

22. Derynck, R., J. A. Jarrett, E. Y. Chen, D. H. Eaton, J. R. Bell, R. K. Assoian, A. B. Roberts, M. B. Sporn, and D. V. Goeddel. 1985. Human transforming growth factor-beta complementary DNA sequence and expression in normal and transformed cells. Nature (Lond.). 316:701-705.

23. Kavanaugh, W. M., G. R. Harsh, N. F. Starksen, C. M. Rocco, and $L$. T. Williams. 1988. Transcriptional regulation of the $A$ and $B$ chain genes of platelet-derived growth factor in microvascular endothelial cells. J. Biol. Chem. 263:8470-8472.

24. Lee, S. L., and B. L. Fanburg. 1987. Glycolytic activity and enhancement of serotonin uptake by endothelial cells exposed to hypoxia/anoxia. Circ. Res. 60:653-658.

25. Lee, S. L., and B. L. Fanburg. 1986. Serotonin uptake by bovine pulmonary artery endothelial cells in culture. II. Stimulation by hypoxia. Am. J. Physiol. 250:C766-C770.

26. Humphries, D. E., S. L. Lee, B. L. Fanburn, and J. E. Silbert. 1986. Effects of hypoxia and hyperoxia on proteoglycan production by bovine pulmonary artery endothelial cells. J. Cell. Physiol. 126:249253.

27. Rounds, S., H. W. Farber, M. L. Render, and F. A. Barnard. 1988. Effects of hypoxia and hypercarbia on cultured endothelial cells. Chest. 93(Suppl. 1):S156-S157. 